\title{
ABRIENDO CAMINO EN LA TUTELA DE DERECHOS FUNDAMENTALES EN MATERIA LABORAL: BUENAS INTENCIONES, MALOS INSTRUMENTOS (JUZGADO DE LETRAS DEL TRABAJO DE COPIAPÓ)
}

\author{
Comentario de Juan Carlos Ferrada Bórquez
}

Copiapó, quince de septiembre de dos mil ocho.

VISTOS:

Que con fecha cuatro de septiembre recién pasado, ante este Juzgado de Letras del Trabajo de Copiapó, se llevó a efecto audiencia de juicio oral en los autos R.I.T. T-12008, por despido vulneratorio de derechos fundamentales, solicitado en procedimiento especial de tutela laboral.

La demanda fue entablada por doña María Natalia Madrid Obregón, cédula de identidad 13.327.394-8, Ito administrativo, con domicilio en Avenida Copayapu No 2750, departamento 11, Copiapó, siendo asistida legalmente por su apoderado don Manuel Catalán Lagos.

La demandada Sociedad de Profesionales Kronos, RUT. 77.207.520-0, fue asistida legalmente y representada por el abogado Nelson Pérez López, con domicilio en Copayapu N 1296, Copiapó.

\section{CONSIDERANDO:}

PRIMERO. Argumentos y pretensiones del actor: Que la demandante solicitó que se declarase su despido como vulneratorio de derechos fundamentales y conforme a ello se estableciera la obligación de su ex empleadora de pagar las indemnizaciones que procedieran de conformidad al artículo 489 del Código del Trabajo.

Fundó tal solicitud en la siguiente relación de hechos que efectuó: "con fecha cuatro de junio de dos mil siete, fue contratada por la empresa Sociedad de Profesionales Kronos Limitada, para cumplir funciones de Ito Administrativo, desempeñándose hasta la fecha de su despido en la faena de construcción, denominada Gran Casino de Copiapó, ubicada en calle Los Carrera $N^{\circ} 2240$, Copiapó, con un sueldo base de $\$ 721.000$, más gratificación por la suma de $\$ 57.000$, más una asignación de colación de $\$ 52.500$ y una asignación de movilización de \$33.600, lo que arrojaba un total de \$ 864.100”.

"Con fecha dos de junio de dos mil ocho, su empleador le comunicó el término del contrato de trabajo por correo certificado, aplicando la causal señalada en el artículo 
$160 \mathrm{~N}^{\circ} 7$ del Código del Trabajo, esto es, incumplimiento grave de las obligaciones que impone el contrato, fundado en que supuestamente habría entregado información confidencial vía electrónica, sin autorización de sus jefes, a personal profesional de la empresa Salfa Construcciones, la cual era su fiscalizada”.

Agrega que los fundamentos entregados por el representante de la empresa, para invocar la causal de despido, demuestran que se ha vulnerado el derecho a la inviolabilidad de todo tipo de comunicación privada, entre los que debemos considerar el sistema denominado MESSENGER, el que respalda en carpetas el contenido de las conversaciones sostenidas con otros contactos de una lista que cada usuario tiene, al cual solo se accede con una clave personal, la que nunca ha proporcionado a persona alguna, y menos a la empresa Sociedad de Profesionales Kronos Limitada, derecho que se encuentra protegido por lo dispuesto en el artículo 19 N N $^{5}$, de la Constitución Política de la República, en concordancia con el artículo 485 del Código del Trabajo.

Finalmente señala que no existe regulación alguna en el contrato de trabajo, ni en el reglamento interno que autorice a la empresa conocer el contenido de los correos enviados y recibidos por los trabajadores.

SEGUNDO. Contestación de la demanda: Que la demandada contestó la demanda en la forma y dentro del plazo contemplado en el artículo 452 del Código del Trabajo, aplicable supletoriamente por disposición del artículo 491 del mismo cuerpo legal, solicitando que ésta fuese rechazada en todas sus partes, con costas, y que se establezca, por el contrario, que no habría en el despido efectuado ninguna vulneración a la garantía contemplada en el $\mathrm{N}^{0} 5$ del artículo 19 de nuestra Constitución Política de la República, específicamente, a la inviolabilidad de las comunicaciones privadas. Fundamenta su solicitud en que carecen de sustento los dichos de la actora, en cuanto a que sufrió una trasgresión al derecho garantizado por la Constitución Política de la República, a saber, el de la inviolabilidad de toda comunicación privada. Así relata que la empresa Kronos Limitada trabaja en la ciudad de Copiapó, contratada por la empresa española EGASA del Grupo Nervion, en labores de fiscalización técnica a la empresa Salfa Construcciones, que construye en esta ciudad el Gran Casino de Copiapó.

En ese entendido la señorita Madrid Obregón habría sido contratada por la empresa como ITO ADMINISTRATIVO, siendo responsable en dichas funciones de llevar a cabo una serie de acciones estratégicas y altamente sensibles.

En este contexto, la actora habría conocido cabalmente el andamiaje administrativo de Kronos Limitada en Copiapó, y manejado información confidencial, cuya divulgación podría significar la pérdida de millones de pesos para su mandante ya referido.

No obstante lo anterior, la señorita Madrid Obregón, desde un computador de uso no exclusivo, en el cual cada usuario tenía las herramientas tecnológicas para restringir la información personal que manejare, envió información confidencial de la empresa a una funcionaria de la empresa contratista, y es más, habría entregado textualmente correos o mail electrónicos enviados por el jefe de proyectos de la empresa, don Jorge León. Reitera que esta información era confidencial y altamente sensible. Este hecho al ser descubierto y, teniendo en consideración que el reglamento interno de la empresa, 
recepcionado en su oportunidad por la actora, señala como deber de todo funcionario "el respetar la empresa y a su representante, en su persona y dignidad, actuando en todo momento con la debida lealtad; considerándose contrario a este deber, el transmitir o traspasar a otras empresas del rubro, informaciones de carácter privado de la empresa en que trabaja”, detonó el despido de la actora.

Explica finalmente que la trabajadora no tomó en consideración que al dialogar electrónicamente por internet a través de un chat, que habría sido el modo en que se envió la información, el sistema crea una carpeta de respaldo que queda almacenada en la carpeta MIS DOCUMENTOS, debiendo restringirse dicha función cuando no se quiere que cualquier persona que use el equipo tenga acceso a la información enviada, sin necesidad de poseer clave de entrada o de acceso. Lo anterior significó que de manera accidental haya sido sorprendida en su actuar. Por lo demás, concluye que a la actora ya se le había representado por la empresa múltiples veces que fuese más cuidadosa con su información privada.

TERCERO. Llamado a conciliación: Se llamó a las partes a conciliación, la que no fructificó en razón de la negativa de la demandada a aceptar cualquier reconocimiento de una vulneración de los derechos que se invocaron como conculcados. Luego ante el mandato consagrado en el artículo 495 del Código del Trabajo, por el cual el juez debe abstenerse de autorizar cualquier tipo de acuerdo que mantenga indemne la conducta lesiva de derechos fundamentales, este juzgador, en particular, prefirió no invitar a la realización de ofrecimientos económicos.

CUARTO. La recepción de la causa a prueba: fijación de los hechos sustanciales, pertinentes y controvertidos. Se determinó en base a las presentaciones de las partes que no discutían la extensión de la relación laboral ni el monto de la remuneración que fue señalada por la actora; por lo anterior se estimó que los hechos a probar debían ser los siguientes:

- Efectividad que el despido se determinó, por el acceso a información, de carácter privado, de la actora, cuyo conocimiento y utilización no era factible para la demandada, sino con una trasgresión a la inviolabilidad de la comunicación privada.

- Para efectos del despido, labores que efectuaba la empresa demandada, entre ellas funciones específicas que cumplía la actora.

- Efectividad de haber enviado la actora información confidencial de la demandada a un tercero, perteneciente a una empresa fiscalizada por esta, específicamente a Salfa Construcciones; eventuales consecuencias que ello podrían generar para la demandada.

- Forma en que la demandada tomó conocimiento de la información que dio origen al despido. Efectividad de tratarse de información confidencial e importante.

- Efectividad de que el computador, desde el cual se extrajo la información en cuestión, era de uso no exclusivo de la actora y que en el reglamento interno de la empresa se encuentra regulado el envío y recepción de correo electrónico, que de alguna forma haga excepción al mandato constitucional de inviolabilidad de las mismas. 
QUINTO. Ofrecimiento de medios probatorios: Que en orden a acreditar sus alegaciones la demandante ofreció e incorporó la siguiente documental: contrato de trabajo celebrado entre las partes; acta de comparendo de conciliación ante la inspección del trabajo e instructivo de uso de elementos informáticos. Además rindió la confesional compuesta por la absolución de posiciones de don Jorge Godoy Frías. Por su parte y con el mismo objeto la demandada ofreció como documental a incorporar el reglamento interno de la empresa y un correo electrónico enviado por la demandante a un tercero; además rindió la testimonial compuesta por los dichos de don Francisco Omar Lagos Peralta y de don Jorge Godoy Frías, más la confesional de doña María Natalia Madrid Obregón. El tribunal en uso de sus facultades oficiosas ordenó a la demandada la incorporación de la carta de despido.

SEXTO. Hecho acreditado y valoración de la prueba: Que ponderada en forma libre la prueba y con respeto a los principios de la lógica, máximas de la experiencia y conocimientos científicamente afianzados, este Tribunal llega al convencimiento en cuanto a que doña María Natalia Madrid Obregón fue contratada con fecha cuatro de junio de dos mil siete por la Sociedad de Profesionales Kronos Limitada, para cumplir funciones de Ito Administrativo. En ejercicio de dicho cargo le correspondía manejar la parte administrativa de la sociedad, ordenando, almacenando y archivando toda la documentación tanto en carpetas de papel como electrónicas. Su jefe directo era don Jorge Godoy Frías, quien se desempeñaba como Inspector Jefe y quien tenía además bajo su mando a un Ito en Terreno. La sociedad en su conjunto trabaja en la ciudad de Copiapó, mandatada por la empresa española Egasa del Grupo Nervión, en la fiscalización técnica de la empresa Salfa Construcciones que construye el Gran Casino de Copiapó.

Físicamente la actora y don Jorge Godoy Frías compartían la misma oficina, utilizando la primera un computador, al cual también tenían acceso otros de los funcionarios, incluido el mencionado Godoy Frías. En específico, la actora sabía que ese computador era utilizado por otras personas, ya que dicha unidad constituía el servidor.

En la sociedad demandada, si bien en un instructivo se señaló, respecto de los equipos que fueron puestos a disposición de los trabajadores, que estaba prohibido cargar software y hardware y que el uso de internet y envío de e-mail era restringido a las actividades a desarrollar en la empresa, en la práctica se permitía el uso de estas herramientas y sistemas de comunicación libremente, sin que existiese ningún tipo de regulación en cuanto a las condiciones, frecuencia y oportunidad para el uso de los mismos; en este entendido los trabajadores de la demandada, incluida doña María Natalia Madrid Obregón regularmente y según sus posibilidades e intereses, utilizaban los equipos computacionales de la sociedad para comunicarse vía Messenger, e-mail y otros.

Que en el entendido anterior, doña María Natalia Madrid Obregón, mantuvo conversaciones vía Messenger en forma frecuente, mientras trabajó en la empresa demandada, con doña Ema Pía Rivera Vergara, quien era su amiga y con quien incluso en el tiempo en que se produjo su despido compartía vivienda. La mencionada Rivera Vergara prestaba servicios, como control técnico - mando medio, sin poder decisorio, ni facultades de administración-, para la empresa fiscalizada por Sociedad de Profesionales 
Kronos, esto es, Empresa Salfa Construcciones, la que desarrollaba en ese entonces el proyecto de construcción denominado Gran Casino de Copiapó.

Se tiene de igual forma por asentado que en fecha no determinada del mes de mayo de dos mil ocho, doña María Natalia Madrid Obregón dentro de las conversaciones que mantuvo desde los equipos comunicacionales de la empresa, vía Messenger, desde su cuenta personal de correo electrónico, con doña Ema Pía Rivera Vergara le comentó asuntos propios del giro de ambas empresas fiscalizadora-fiscalizada, específicamente del siguiente tenor: páginas 35 y 36, MAYO, PIA_DE_LOS_ANGELES@HOTMAIL. COM "recién J. León le mandó un mail a Matías repesao" -envíamelo para verlo- "Estimado Matías: respecto a tu reclamo por la demora en la revisión de estados de pago y presupuestos de obras extras, que tiene con déficit de caja, y que según entendí, atribuyes a una mala disposición de la ITO, quiero reiterarte lo que ya te señalé al respecto, y que te resumo: 1. Esta inspección no tiene ni actúa con ninguna intencionalidad para perjudicar o complicar a la Constructora. 2. Cualquier eventual demora en alguno de estos procesos, sólo obedece a alguna dificultad puntual causada por necesidades o situaciones propias de obra, tales como: priorización puntual de otros requerimientos en beneficio del avance de la obra; generación de mayor cantidad de EP, por condición especial de contrato, generación y simultaneidad de gran cantidad de OOEE; algunas deficiencias en presentación de antecedentes de respaldo, disminución de nuestra disponibilidad efectiva, motivada por entregas demorosas y re entregas que podrian evitarse, etc. 3. No obstante que las bases establecen que deberíamos revisar EP una vez entregados todos los antecedentes, incluidos los provisionales, justamente hemos diferido este proceso para facilitar, ayudar y agilizar el proceso; sin embargo y como podrás ver en el cuadro adjunto, siempre e independientemente de cuento demoremos en revisar los EP, uds. presentan una demora adicional a la presentación del resto de los antecedentes, bastante importante en muchos casos (desde 7 a 37 dias) que dilata y pospone el proceso de dar curso al periodo de pago de cada EP, según lo fijado por las bases, siendo este lapso de tiempo el más relevante en la generación del déficit que señalas. 4. Respecto de las OOEE, afectadas por los mismos conceptos, te puedo asegurar que hacemos los mayores esfuerzos por ir resolviendo su situación con la mayor premura, en la medida que el proceso de EP, recepciones y cooperación de $U d s$. respecto a la información requerida, lo posibiliten así. En todo caso esperamos quedar al día con nuestra revisión a más tardar el 10 de junio. Esperando que los números te aclaren que las demoras mayores no corren por nuestra cuenta ni intención, sino más bien dependen de Uds., te saluda Jorge León Navas, Jefe de Proyectos, Kronos Ltda.". "Prefiero enviarlo así por más cuidado, no le digas a Passi porque el mail era sólo para Matías y David R.” -ya o.k.

En la misma línea anterior, se encuentra establecido que el correo antes referido fue enviado en forma personalizada, y por tanto exclusiva, por la actora a la mencionada señorita Rivera Vergara, no existiendo ninguna manifestación de voluntad, de ambas, tendiente a que esta conversación fuese conocida por terceros.

Que en fecha no determinada, pero anterior al día dos de junio de dos mil ocho, don Jorge Godoy Frías, buscando unos documentos que necesitaba, ingresó al computador de uso no exclusivo, que utilizaba doña María Natalia Madrid Obregón, en ausencia de ésta, utilizando para ello su propio usuario, password o clave, y al dirigirse a la carpeta MIS DOCUMENTOS, ingresó a una carpeta llamada MIS LOOGS, donde se dio cuenta 
que se encontraban almacenadas una serie de conversaciones que había mantenido la señorita Madrid Obregón con terceros y que se habían respaldado sin el conocimiento y consentimiento de ésta. Luego de lo cual en vez de cerrar dicha carpeta y ponerlo en conocimiento de la afectada, decidió revisar todas las conversaciones que ésta había mantenido con terceras personas, correspondientes, por lo menos, a los últimos meses trabajados y consistentes, al menos, en más de treinta y cinco hojas, llamándole, especialmente la atención, la conversación reproducida previamente con la señorita Ema Pía Rivera Vergara de páginas 35 a 37, por conocer que se trataba de una funcionaria de la empresa fiscalizada por ellos. Acto seguido, en virtud de ese hallazgo y por estimar que ese actuar ponía en entredicho la confianza que se tenía a la referida trabajadora, se decidió despedirla, invocando para ello como causal un incumplimiento grave de las obligaciones laborales, que lo hicieron consistir, como reza la carta de despido, en la entrega comprobada de información confidencial por vía electrónica, sin autorización de sus jefes y por conducto totalmente irregular, a personal profesional de la Empresa Constructora Salfa Construcciones, de la cual son la inspección técnica.

Finalmente, se encuentra asentado con la prueba rendida, que ni en el contrato de trabajo ni en el reglamento de orden, higiene y seguridad de la empresa, existe una regulación expresa del uso de los medios tecnológicos -computadores y recursos que proporciona internet e intranet-, ni tampoco existe una regulación o procedimiento para la revisión de la información almacenada en los computadores que sean de carácter privado de los usuarios; en ese entendido, no existe prohibición alguna relativa a guardar información privada en una carpeta del computador, ni menos una norma que autorice a revisar esa información privada o a invocarla para establecer una sanción. Por el contrario, sí queda asentado que en dicho reglamento dentro de las obligaciones del trabajador está el respetar a la empresa y a sus representantes, en su persona y dignidad, actuando en todo momento con la debida lealtad. Considerándose infracciones a este deber el transmitir o traspasar a otras empresas del rubro, informaciones de carácter privado de la empresa. Asimismo, que dentro de las prohibiciones del trabajador no se contempla ninguna relativa al asunto debatido y que en un ítem denominado confidencialidad se señala que toda la información, ya sea de propiedad de la empresa o de sus clientes, que entregue Kronos a su personal para el desarrollo de sus funciones, así como también aquella información que se genere durante el desarrollo de los servicios es confidencial, por lo que no podrá ser entregada a terceros, ya sea en papel o en medios magnéticos, sin la autorización de la administración de Kronos o del representante del cliente. Por último en el ítem de Sanciones y Amonestaciones se contempla que las sanciones asociadas a las infracciones de las normas referidas son la amonestación; siendo la terminación del contrato una decisión que depende de la gravedad, poniéndose como ejemplo la falta de lealtad a la empresa en cualquier circunstancia.

a) En cuanto a la alegación de que la información utilizada para fundar el despido se habría OBTENIDO con vulneración de derechos fundamentales de la trabajadora, específicamente transgrediendo la inviolabilidad de toda forma de comunicación privada. Al respecto no fue posible, a través de la prueba rendida, formarse convicción, por carencia de medios probatorios que así lo demostrasen, que el conocimiento de las conversaciones 
privadas de doña María Natalia Madrid Obregón con terceros, se OBTUVO a través de medios ilícitos o a través de actos que impliquen violación de derechos fundamentales. En específico, no se logró acreditar, como lo alegó la demandante, que en algún momento alguien, aprovechando quizá un descuido de ella, ingresó a su correo privado, momentáneamente abierto y conectó la función de Messenger, destinada a respaldar en una determinada carpeta -MIS DOCUMENTOS-, sus conversaciones, para así poder revisarlas con posterioridad; menos se pudo establecer que, puntualmente, el día cuatro de junio de dos mil ocho, como lo señaló en la Inspección del Trabajo, ella no se haya conectado a Messenger, y que contrariamente amigos suyos hayan constatado lo contrario. En efecto, sólo la actora a través de su confesional señaló tal hipótesis, la que no pudo corroborarse, pero con lo cual, al menos, quedó totalmente claro, que ella no fue quien le pidió a dicho sistema de conversación que efectuara tales respaldos. Dicha hipótesis fue negada por quien habría realizado el hallazgo supuestamente accidental don Jorge Godoy Frías, sosteniendo que jamás incurrió en tal conducta y que si se produjo tal respaldo fue por desconocimiento de la trabajadora de cómo opera este tipo de sistema de comunicación unido a su propio descuido. Al respecto se refirió también uno de los testigos de la demandada, don Francisco Lagos Peralta, quien señaló que existen distintos tipos de versiones de dicho sistema de conversación, en unos de ellos sería necesario expresamente darle la función para que se produzca el respaldo; en cambio en otros no. Relativo a este punto ninguno de los deponentes ni absolventes pudo aclarar al tribunal qué versión en específico sería la que está cargada en el computador en cuestión. Con lo anterior, al no haber quedado acreditado el supuesto de hecho -obtención con una vulneración tan evidente- que fundaría una exclusión valorativa de la prueba ingresada por la demandada -respaldo de conversaciones entre la actora y terceros-, necesariamente deberá desestimarse la solicitud esgrimida de que no se diera valor probatorio a dicho documento.

b) En cuanto al establecimiento de los hechos que sí se dieron por probados. De un análisis íntegro de la prueba documental incorporada, este juzgador llegó al convencimiento de que ambas partes casi coincidían en los hechos que fueron presentados al tribunal, no cuestionando con ello la información contenida en cada uno de los documentos, toda vez que lo que ellos contenían reflejaban en gran parte lo expuesto por cada uno de los litigantes en su respectiva demanda y contestación de la demanda. En efecto, el contrato de trabajo incorporado dio cuenta con claridad de los elementos básicos de la relación, esto es, inicio del contrato, naturaleza del mismo, funciones del trabajador, jornada, prestaciones y otros; a su vez el reglamento interno permitió formarse convicción de las obligaciones y prohibiciones que tenía el trabajador, como asimismo de las posibles sanciones que podían ir asociadas a sus incumplimientos. También ese mismo reglamento permitió constatar las omisiones, falencias o vacíos que éste presentaba en cuanto a la regulación de materias relativas al control, a través de medios idóneos y generales, con respeto a los derechos fundamentales del trabajador, de la utilización de la información privada que a través de los medios tecnológicos aportados por la empresa, pudiese enviarse a terceros o simplemente almacenarse en esos equipos. A la misma constatación se pudo llegar a través del documento individualizado como Instructivo de la Empresa Kronos, el 
cual si bien hacía referencia específica, en un ítem, al uso de elementos de informática, fue desvirtuado por el resto de la prueba rendida, ya que tanto las absoluciones de don Jorge Godoy Frías, jefe de la trabajadora afectada -prueba de la demandante-, como la absolución de esta última - prueba del demandado-, coincidieron en que se utilizaba con perfecto conocimiento de toda la jefatura internet e intranet, para fines personales, sin mayor control ni objeción. Consecuentemente, no se discutió la efectividad de haberse mantenido, a través de Messenger, conversaciones entre la actora y doña Ema Pia Rivera Vergara, ni tampoco que, puntualmente, se haya mantenido la conversación que fue respaldada en el mismo equipo en la carpeta MIS LOOGS de la carpeta MIS DOCUMENTOS y que fue conocida a través del respectivo respaldo de conversación que se incorporó y que fuera referida al momento de dar por asentados los hechos fijados por el tribunal. Por último, los documentos carta de despido y acta en comparendo ante la Inspección del Trabajo, permitieron conocer cuál fue la decisión, inspirada en las distintas interpretaciones que hicieron de los hechos ya referidos, por parte de doña María Natalia Madrid Obregón, que estimó que se vulneraba su intimidad al acceder a sus conversaciones privadas y de la Sociedad de Profesionales Kronos que vio en dicha información una entrega de información confidencial grave e intolerable.

\section{SÉPTIMO. Razonamiento respecto a la carga procesal probatoria de la demandante: la exigen-} cia de indicios. Según ya se ha esbozado, uno de los principios más fuertemente recogidos con la reforma procesal laboral, es el de la tutela judicial efectiva de los derechos de los trabajadores, siendo en esa vertiente de pensamiento que se justifican otros de los principios de la misma, como oralidad, inmediación, gratuidad, celeridad, oficialidad con función cautelar y probatoria del juez, etcétera. Con todo, el alcance de este principio de tutela judicial efectiva es mucho mayor del que aparece a simple vista y que en forma tan evidente se expresa en los principios recién apuntados; en efecto, existen otras consecuencias jurídicas, recogidas por nuestro legislador laboral, que son fruto directo de esta lógica de protección integral hacia la parte más débil. Por cierto que este posicionamiento normativo no es de creación propia de nuestro legislador, sino que viene aprehendido de un establecimiento serio y consolidado del derecho comparado, relativo al difícil escenario probatorio en que se encuentra el trabajador al momento de efectuar una denuncia por violación o lesión de derechos fundamentales, dificultad que evidentemente emana, como lo destaca nuestra doctrina, de la situación estratégica en que se encuentra el empresario sobre la prueba, derivado de la proximidad y dominio que tiene la mayoría de las veces sobre ella. El no reconocimiento de la situación antes descrita, hubiese significado una evidente merma al principio de tutela judicial efectiva referido, toda vez que habría contenido en sí misma una traba procesal que colocaría muchas veces al trabajador en la imposibilidad de lograr un resultado judicial favorable. Es por ello, que haciéndose cargo de lo anterior, nuestro legislador laboral en el artículo 493, introdujo una reducción probatoria, consistente en la obligación del trabajador de presentar sólo indicios suficientes de la vulneración que alega. Esta técnica, como lo ha señalado José Luis Ugarte Cataldo, no se trata de una inversión del onus probandi, ya que no basta la alegación de una lesión a un derecho fundamental, 
para que se traslade al empleador la carga probatoria, sino que sólo se alivia la posición del trabajador exigiéndole un principio de prueba por el cual acredite indicios de la conducta lesiva, esto es, acredite hechos que generen la sospecha fundada, razonable, de que ha existido esta lesión.

Reconocido lo anterior, es necesario, en consecuencia, despejar como primer tema relevante si la demandante cumplió con este estándar probatorio exigido. Acá debe destacarse, que la carta de despido incorporada y que da cuenta de la causal y de los hechos esgrimidos para poner término a la relación laboral, alude directamente a la entrega -comprobada- de información por vía electrónica por un conducto irregular. Luego en el acta levantada ante la Inspección del Trabajo la trabajadora reclama que esta información comprobada, a que alude la empresa, correspondería a una conversación instantánea que por Messenger tuvo con una amiga, la cual estima, se habría obtenido violando su contraseña de su cuenta particular, ya que en ningún momento ella ha autorizado a la empresa para leer su información privada y nunca ha respaldado sus conversaciones. En la misma acta introducida por la actora, se consigna la respuesta de la sociedad demandada, la que señala que efectivamente tiene pruebas escritas de una conversación electrónica entre la trabajadora y la funcionaria de Salfa Construcciones, documento en el que fundarían su decisión de despido. Agrega al respecto que en ningún momento se habría violado una clave o contraseña privada de la trabajadora, sino que se accedió a esta información a través de un respaldo generado en la carpeta MIS DOCUMENTOS, a la cual se habría llegado fortuitamente luego de la búsqueda de otros antecedentes. En el mismo sentido, la absolución de posiciones de Jorge Godoy Frías ilustró al tribunal en cuanto a que él con la demandante operaban un mismo computador, ya que estos no son de uso exclusivo y que cada funcionario de la empresa tenía una clave personal para ingresar a estos equipos. Los computadores estaban habilitados para navegar por internet y además se trabajaba con intranet para los asuntos de la empresa. Preguntado respecto a un correo personal de la trabajadora Madrid Obregón-Nmadrid8@hotmail. com, señaló que conoció ese correo por que en una carpeta MIS LOOGS de la carpeta MIS DOCUMENTOS en el escritorio del computador, existían archivos de este correo a los que accedió, sin requerir de una clave. Señala que encontró esa información de casualidad, buscando información propia; agrega que al ver esa información, le llamó la atención, por lo que revisó unos dos o tres días de conversaciones; ahí encontró la conversación que invocó como fundante del despido, la cual al verla inmediatamente se dio cuenta que correspondía a una conversación entre la señorita Obregón con Ema Pía.

Del análisis de la prueba anteriormente referida, este juzgador tiene por establecido que existen antecedentes suficientes, para al menos estimar a priori, que eventualmente, el despido de María Natalia Madrid Obregón pudiese estar fundado en la utilización de información de carácter privado, toda vez que queda en evidencia que esta información correspondía a una conversación entre la trabajadora afectada y un tercero, la cual circunstancialmente quedó respaldada en una carpeta del escritorio del computador, pero que en ningún caso, ello significa, que por esa situación, la información pasa a transformarse en pública, ya que para que ello pudiese estimarse, necesariamente, se requeriría una manifestación de voluntad de la parte emisora y receptora, o al menos de 
una de ellas; por lo que a falta de dicha manifestación debe entenderse que la información sigue siendo privada, ya que en ella por las características que envuelve-comunicación electrónica escrita y directa de una persona determinada a otra, también determinada, por un medio cerrado- demuestra una voluntad tal de excluir del conocimiento de lo comunicado a terceros, que de haberse estimado que alguien podría haber interferido en dicha comunicación, conociéndola de cualquier modo, lo más probable es que no la hubiesen realizado. A mayor abundamiento, el ciudadano común y corriente, en muchas de las actividades que desarrolla a diario, en ámbitos de privacidad, lo hace bajo la confianza, con la razonable expectativa, de que este sector de su vida no será interferido por terceros, ya que la sola posibilidad de que ello suceda, le haría moldear su comportamiento a tal extremo que su libertad para determinarse y comportarse no sería tal, ya que sería temeroso de que saliera a la luz, lo que él ha querido que sea secreto. Así respecto a la inviolabilidad de los medios de comunicación se ha señalado que ella descansa sobre los principios de autonomía, dignidad e intimidad de la persona, que se traduce en una esfera de derecho formada por aquellos fenómenos, comportamientos, datos y situaciones de una persona, que normalmente están sustraídos del conocimiento de extraños y cuyo conocimiento por estos puede turbarla moralmente por afectar su pudor y su recato, a menos que esa misma persona asienta en ese conocimiento.

Luego en este análisis cabe preguntarse, si es que varía lo antes razonado, la circunstancia de que lo comunicado no sea información personal, sino que sea una conversación referida a temas que competen por ejemplo a la empresa; y si varía la circunstancia el hecho de que la información se haya encontrado en un respaldo el cual no sería el vehículo de comunicación mismo.

Respecto de la primera interrogante, y partiendo del supuesto de que la obtención de esta información sea a través de un hecho fortuito y no premeditado o infractor de mecanismos de seguridad, debiese estimarse que en primer término, nuestra legislación, más allá del contenido mismo de la comunicación privada, lo que garantiza en este caso, es que no se produzcan invasiones a la intimidad que sean irracionales y desproporcionadas, con lo cual ya envía un mensaje relativo a que existe una prohibición de acceder, utilizar e invocar cualquier información contenida en estos canales privados, cuando ello pudiese significar el desconocimiento del derecho en su esencia. Luego si la transgresión es tan insoportable, por afectar el núcleo mismo del derecho protegido, será irrelevante el contenido de la comunicación, por lo que incluso, refiriendo temas que pudieran interesar a la empresa, no podrían ser utilizados ni invocados. Por el contrario si esta vulneración es más sutil, más tenue y por lo mismo sólo implica una afectación de determinadas manifestaciones del mismo, podrá ser aceptada en la medida que sea racional y proporcionada, donde normalmente la racionalidad estará dada por la necesidad de compatibilizarlo con otros bienes y derechos; en ese sentido podría ser eventualmente aceptada la utilización de la información que se refiere a la empresa. Finalmente, para la segunda interrogante, se debe asumir, como ya se señaló, que no por que circunstancialmente esta comunicación privada se haya respaldado en un archivo que ya no sería el vehículo de comunicación mismo quiere decir que está información es pública, ya que ella todavía expresa las aspiraciones de alguien que siempre pensó mantenerlas en el ámbito 
de lo privado, siendo totalmente irrelevante que no contenga ella una clave, cerradura, cierre u otro mecanismo de seguridad, toda vez que la simple actividad de observación permite formarse la conciencia y claridad de que esa información no está dirigida hacia su persona, como ocurrió en el caso propuesto, donde era evidente que se trataba de un correo que no le pertenecía al lector ocasional, a menos que hubiese pretendido llamarse María Natalia o Ema Pia, con lo cual su eventual utilización también debe responder al análisis de cuanto ello produce una lesión en el derecho tutelado constitucionalmente.

OCTAVO. Razonamiento respecto de la obligación de la demandada de explicar los fundamentos de las medidas adoptadas y su proporcionalidad. En cierto modo las reflexiones efectuadas en el acápite previo, nos permiten hacer una nueva constatación, que en todo caso ya ha sido efectuada por autores como Eduardo Caamaño Rojo, en el sentido de que los derechos fundamentales, sean específicos, inespecíficos, laboralizados o no, no son absolutos y por lo mismo reconocen como límite el ejercicio de otros bienes o garantías constitucionales; en razón de ello, en su ejercicio y siempre teniendo presente que nunca se puede afectar el núcleo irreductible de un derecho fundamental -lo conocido en doctrina como el límite a los límites-, en el ejercicio de uno de estos derechos puede producirse un conflicto con otros derechos o bienes constitucionalmente protegidos.

Con lo anterior se responde la interrogante de si los derechos fundamentales reconocen algún tipo de límite o morigeración en el particular ámbito de la empresa, por lo que corresponde cuestionarse ahora cuando el ejercicio del poder empresarial puede concretamente llegar a producir la afectación referida.

Tal como lo ha señalado la Dirección del Trabajo en Dictamen 8237-1995, el sistema jurídico ha dotado al empleador de lo que la doctrina llama el poder de dirección y de disciplina, esto es, la facultad de dirigir y mantener el orden dentro de la empresa. Estos poderes reconocen su fundamento en el derecho constitucional de propiedad y en la libertad para desarrollar cualquier actividad económica; sus objetivos son dotar al empresario del poder de iniciativa económica con libertad para contratar trabajadores, adaptarse a las necesidades del mercado, controlar el cumplimiento y ejecución del trabajo convenido y sancionar en última instancia.

Es en virtud de los poderes empresariales antes referidos, que se pierde el equilibrio en la relación entre particulares, pasando a desarrollarse esta relación en un ámbito de subordinación y dependencia, propia del derecho público y de las relaciones entre el Estado y un particular, -quizá por ello, en este ámbito, sea tan nítida la discusión de los derechos fundamentales, nacidos precisamente en un Estado de derecho como límite al poder estatal-, por lo que esta tensión es la que pasa a constituir el punto de partida para la colisión de los poderes empresariales y de los derechos fundamentales del trabajador.

Luego de lo razonado, es ineludible que el objeto de este juicio es determinar si fue justificado el accionar del empleador en el ejercicio de sus facultades legales -leer el respaldo de una conversación privada y luego utilizarla públicamente- o si esta vulneración al trabajador -inviolabilidad de toda comunicación privada- no es aceptable amparado en sus derechos fundamentales, esto es en aquellos derechos que por su trascendencia 
y jerarquía dentro del conjunto de los que son atribuidos a la persona, constituyen un núcleo central, esencial, que debe ser protegido de manera especial y fuerte frente al ataque de terceros.

Ante esta colisión de derechos, debe primero consultarse en la legislación nacional, si es que existe alguna norma que resuelva el conflicto, ya que de ser así el método de solución del mismo será por vía de la subsunción. La verdad es que no existe tal norma, sólo podemos encontrar como referencia las normas dispersas que van conformando los poderes de dirección y disciplina referidos -artículo 12, 24, 153 y otras- y el inciso segundo del artículo quinto del Código del Trabajo que señala que el ejercicio de las facultades que la ley le reconoce al empleador, tienen como límite el respeto a las garantías constitucionales de los trabajadores, en especial cuando pudieran afectar la intimidad, la vida privada o la honra de estos. A lo anterior debe sumarse el inciso final del artículo 154 del cuerpo legal citado a propósito de las menciones que obligatoriamente debe contener el reglamento interno de la empresa, que dispone que toda medida de control, sólo podrá efectuarse por medios idóneos y concordantes con la naturaleza de la relación laboral y, en todo caso, su aplicación deberá ser general, garantizándose la imparcialidad de la medida, para respetar la dignidad del trabajador. En conclusión, si bien encontramos normas que aluden a esta tensión, no existe ninguna que en definitiva la resuelva para el caso concreto, con lo cual queda excluida la posibilidad de resolver subsumiendo el caso concreto en esa determinada norma general. A partir de ello, en la mayoría de los ordenamientos jurídicos, incluido el nuestro, se ha impuesto el método de la ponderación guiado por el principio de proporcionalidad en sentido amplio, creado por la jurisprudencia alemana, principalmente a partir de los escritos de Robert Alexy, el cual consiste básicamente en pesar los derechos y bienes en juego, persiguiendo que cada derecho se sacrifique por el otro en la menor medida posible y sólo en la medida que ese sacrificio sea racional y no afecte el ya mencionado núcleo esencial de los derechos fundamentales.

Esta ponderación a través del principio de proporcionalidad en sentido amplio, opera a través de tres subjuicios: el de la adecuación, el de la necesidad y el de la proporcionalidad en sentido estricto. Si hecho el examen aludido la conducta del empleador supera esos tres estándares establecidos, se podrá decir que prima el derecho del empleador y que no ha existido afectación sancionable de los derechos fundamentales del trabajador; por el contrario, si no resiste alguno de esos análisis, la conclusión inevitable es que el actuar del empleador es prohibido por nuestro ordenamiento jurídico por ser vulneratorio inaceptablemente de los derechos fundamentales que asisten al trabajador.

a) El Juicio de Adecuación. A través de esta valoración se busca establecer que la medida sea idónea, apta para el fin perseguido por el empleador; con lo cual la restricción al derecho fundamental del trabajador permite alcanzar un fin empresarial legítimo. En nuestro caso en estudio, la pregunta pertinente es si es legítimo que el empleador pretenda controlar los medios tecnológicos -equipos de computación- que siendo de su dominio, pone a disposición de los trabajadores para el desarrollo del trabajo mismo; luego más específico que ello, que además desee controlar las herramientas que proporciona el sistema computacional, pero que no son gratis, sino que tiene un costo para él, como los son por ejemplo internet y 
otros; y finalmente la pregunta que nos interesa, si es legítimo que el empleador quiera evitar que información propia de su giro y en casos confidencial sea conocida por terceros. Claramente la respuesta a estas tres interrogantes es afirmativa, con lo cual podemos constatar que detrás de este reconocimiento está presente la protección al derecho de propiedad del empleador; luego es requisito preguntarse si es apto o idóneo para lograr tal protección, la fiscalización y control que realice el empleador al uso de los equipos y a la información que se envíe desde ellos a terceros; en otras palabras, si con revisar los respaldos de las conversaciones que los trabajadores tienen a través del sistema Messenger con terceros, se puede evitar que no se traspase información privada y sensible para la empresa y, además, que no se de un uso inadecuado a estas herramientas, por ejemplo, que no se cumplan las labores por pasar todo el día en un chat. La respuesta evidente es que a través de esa fiscalización y control, se llega, sin duda, a evitar que a través de estos medios electrónicos no se cumplan estas legítimas expectativas del empleador; en el caso concreto, la lectura efectuada por don Jorge Godoy Frías del respaldo de la conversación por Messenger entre doña María Natalia Madrid Obregón y un tercero, sin su consentimiento y, su posterior utilización contra ella, evidentemente le permiten proteger a la empresa de que ésta no haya estado traspasando información confidencial de Sociedad de Profesionales Kronos Limitada a cualquier tercero, incluida la Constructora Salfa; incluso esta revisión, le permite saber cuánto estuvo conectada a Messenger y con ello, con quiénes se relacionó y cuánto tiempo no dedicó a su labor efectiva dentro de la empresa.

b) El Juicio de Necesidad. Por esta valoración se persigue establecer que la medida o restricción del derecho fundamental, sea indispensable para lograr el fin legítimo, no existiendo una alternativa menos costosa; así deben siempre preferirse las medidas no invasoras de derechos fundamentales. Acá debemos preguntarnos si es posible que la Sociedad de Profesionales Kronos Ltda. llegara a conocer por otros medios que su trabajadora se comunicaba con una trabajadora de la empresa Salfa Construcciones vía Messenger si no hubiese leído los respaldos de dichas conversaciones. La respuesta rotunda es no, toda vez que las posibilidades en estos casos son muy limitadas, ya que se trata de conversaciones instantáneas, a través de un mecanismo electrónico -como muy bien lo reconoció el testigo Francisco Lagos Peralta "es como un teléfono con escritura", donde las únicas opciones distintas serían más graves y vulneratorias como por ejemplo intervenir directamente el Messenger - si es que se pudiese- o derechamente tener un vigilante toda la jornada de trabajo, que estuviese constatando que no se hable con terceros. De lo anterior, que evidentemente la menos invasiva resulta ser la lectura y utilización de los respaldos de la conversación privada.

c) El Juicio de Proporcionalidad en sentido estricto. Finalmente a través de esta valoración se busca establecer que la limitación al derecho fundamental del trabajador sea racional, no desproporcionada, que se pueda justificar tanto el objetivo de la medida como sus efectos. Así de partida, queda inmediatamente excluida la posibilidad de limitar el derecho fundamental en su núcleo esencial, sometiéndolo 
a exigencias o restricciones que lo hagan irrealizable. Así en este caso, sería inaceptable bajo todo punto de vista que se hubiese producido el conocimiento de la información utilizada por el empleador, a través de la obtención dolosa de la contraseña o password, o introduciendo otro mecanismo en las mismas condiciones que violaran la privacidad.

En este examen, necesariamente debe recordarse el dictamen $\mathrm{N}^{\circ} 260-2002$ de la Dirección del Trabajo, el cual señaló, ejemplificando, que lo habitual es que el empleador no pretenda enterarse del contenido de las llamadas telefónicas de sus dependientes, por mucho que la línea y el aparato mismo le pertenezcan; lo mismo es extensivo a otras dependencias físicas específicas y por cierto a otros medios de comunicación, donde debe comprenderse sin duda el uso del correo electrónico y del sistema messenger. Luego la conclusión inevitable es que para que pueda pretender enterarse del contenido de las conversaciones de sus trabajadores debe tratarse de situaciones muy justificadas y por tanto excepcionales. Una de ellas podría ser como ya se ha visto la protección de información confidencial y de las estrategias y secretos de la empresa.

Este mismo dictamen señala tajantemente que en ningún caso el empleador puede tener acceso a la correspondencia electrónica privada enviada y recibida por los trabajadores -límite a los límites-, para a continuación señalar que excepcionalmente el empleador podría conocer los correos enviados desde el servidor de la empresa, pero siempre que se cumpla como requisito previo que ello sea regulado en el reglamento interno en forma expresa. Así en el reglamento interno debe regularse las condiciones, frecuencia y oportunidad del uso de estos medios electrónicos; en el mismo reglamento puede estatuirse que todos los correos - enviados del servidor- vayan con copia a la gerencia; finalmente que se regule el uso extraproductivo de los mismas herramientas proporcionadas por estos sistemas.

A su vez debemos recordar, en esta parte del análisis, el inciso final del artículo 154 del Código del Trabajo, que dispone que toda medida de control, sólo podrá efectuarse por medios idóneos y concordantes con la naturaleza de la relación laboral y, en todo caso, su aplicación deberá ser general, garantizándose la imparcialidad de la medida, para respetar la dignidad del trabajador.

Vayamos a nuestro caso concreto. La prueba documental rendida, como ya se analizó, en ninguna parte ilustró a este juzgador en el sentido de que se haya establecido en el reglamento interno, que las conversaciones electrónicas de los trabajadores, efectuadas desde equipos computacionales de la empresa, serían respaldadas en archivos que convertirían esta información en pública. Si se hubiese establecido tal advertencia, quizá ello pudiese haber llegado a justificar la utilización contra el emisor de su información, ya que éste sabría desde antes que existe esa posibilidad y por lo mismo habría moldeado su actuar a tales exigencias. Es dable preguntarse entonces, si alguien podría pensar que la señorita Madrid Obregón, de haber sabido que existía tal advertencia en el reglamento interno ¿habría reproducido a su amiga ese mail de don Jorge León Navas, poniendo en riesgo su trabajo?, evidentemente que no. Y si emitió esa comunicación y tantas otras más, lo hizo, que duda cabe, en la confianza de que dicha conversación se mantendría en el ámbito de lo estrictamente privado. Ilustrador al respecto son los dichos de la 
misma afectada cuando afirma que en ese periodo ella vivía con Ema Pía -la receptora de la información- y que de haber querido hacer algo malo -traspasar información confidencial- sin que fuese conocido por sus jefes, podría perfectamente haber esperado que llegase el término de la jornada para luego en el hogar entregarle esa información; por el contrario si lo hizo a través de Messenger fue en la confianza de que nadie sabría de esta conversación porque entendía que era privada - de hecho se lee en el respectivo respaldo de la conversación que pide que esto no lo comente a nadie pues fue enviada exclusivamente a Matías y David R. Conclusión de lo anterior, es que la actividad de don Jorge Godoy Frías presenta un primer problema para autojustificarse, cual es el hecho de que si es que se quería ejercer ese control debía estar previsto en el reglamento interno y no lo estaba. Así no basta en este punto el compromiso y lealtad mostrado hacia la empresa por don Francisco Omar Lagos Peralta, cuando señaló que en todos los trabajos estaría prohibido almacenar información personal dentro de los equipos de la empresa y que a su juicio, la información personal pasa a ser pública cuando se deja en el disco duro de un computador, ya que a ella puede acceder cualquiera. Evidentemente el razonamiento vertido por él pierde sustento frente a la interpretación ya efectuada por la Dirección del Trabajo y, por lo demás, porque él no reconoce que un respaldo de una conversación por Messenger sigue dentro del ámbito de lo privado, toda vez que como se refirió no se ha manifestado consentimiento de hacerlo público y porque de una simple ojeada él y don Jorge Godoy Frías, como ambos lo reconocieron, pudieron ver en el encabezado, antes de revisar el contenido, que era una comunicación dirigida por doña María Natalia a doña Ema Pía. Lo prudente habría sido cerrar dicha comunicación y haber dado cuenta a su compañera de trabajo de que se había producido accidentalmente ese respaldo; o siendo desconfiados ¿qué fines se perseguían leyendo sus conversaciones?, pareciera que más allá del morbo que ello pudiese representar, finalmente se produjo una inaceptable desviación de la inocente lectura, pasando a constituirse en el fundamento de la desconfianza y la consecuente pérdida de la fuente laboral.

Luego la actividad del empleador, a través del señor Godoy Frías, no solo es cuestionable en la forma que se ha planteado, también en lo que sigue: luego de revisar el contenido de todas las conversaciones respaldadas de la señorita Madrid Obregón, sin su consentimiento, como se estableció no menos de 37 HOJAS, se determina utilizar éstas en su contra, según ellos por la gravedad de los hechos que contenían y que significaron una perdida de confianza intolerable, en palabras de don Jorge Godoy Frías, ya que ellos tenían estrategias importantes que no podía ser desviadas a canales no autorizados, ya que ello les podría significar perder el contrato con su mandante, etcétera; no obstante y fundando supuestamente la causal invocada "entrega comprobada de información confidencial a personal profesional de Salfa por un conducto irregular", sólo se incorporó, como se estableciera en el considerando sexto, el correo extensamente descrito en el referido considerando, el cual a todas luces por su texto se trataba de una información ya enviada a Salfa Construcciones, así por lo demás quedó refrendado de la confesional de la señorita Madrid Obregón y del señor Godoy Frías. Luego la tal entrega de información confidencial a la fiscalizada no era tal, toda vez que Salfa ya contaba con dicha información, con lo cual es del todo irrelevante que se le envíe nuevamente. Con todo, 
para salvar esta situación, se esbozó por los testigos Godoy Frías y Lagos Peralta que lo cuestionable era que esta información iba dirigida a la gerencia de la empresa Salfa y no a un mando medio; con lo cual surge la pregunta de si la demandada en verdad velaba por sus intereses o los de Salfa, ya que a lo más a ésta última pudiese serle desagradable tal filtración. A mayor abundamiento, el texto de la comunicación utilizada para fundar el despido, no refiere ninguna estrategia, ni ninguna información secreta y ni siquiera algo importante, sólo se trata de un correo en el cual se reiteran excusas fundadas en la divergencia existente en los puntos de vista de ambas empresas, las cuales son propias de una relación de trabajo, pero en nada demuestran una determinada línea de acción o de posibles consecuencias. Por lo anterior, resulta desproporcionado que se haya decidido, pasar por alto que dicha información estaba contenida en un respaldo accidental de una conversación electrónica privada, para luego leerla completamente e invocarla como causa del despido, toda vez que la gravedad invocada en el supuesto actuar de la trabajadora y la necesidad de protección de la empresa frente a ello, no se condice de ningún modo con la protección esperable hacia la garantía de inviolabilidad de las comunicaciones privadas.

No es un obstáculo al razonamiento anterior, la proyección que efectúa el empleador, relativa a que quizá cuánta más información habrá comentado la trabajadora, toda vez que ha quedado demostrado que pudiendo acceder al respaldo de al menos 37 hojas de conversaciones privadas, la demandada no ha encontrado nada más que le mereciera la opinión de presentarla al juicio, con lo cual, como se señaló, la entrega de información confidencial, no ha sido más que aquello que refirió la trabajadora afectada una conversación privada donde a modo de "cahuín” de chisme, se remitió dicho e-mail, no alcanzando en caso alguno los ribetes que ha querido mostrar la empresa. Por lo demás esta pérdida de confianza alegada, por cierto que jamás podría fundar por sí misma el despido, toda vez nadie refirió que doña María Natalia haya estado contratada a través de la modalidad de cargo de exclusiva confianza de aquellos que refiere el inciso segundo del artículo 161 del Código del Trabajo. Tampoco constituye un obstáculo la obligación de abstención de transmitir o traspasar información, contemplada en el reglamento interno, ni la alusión extensiva a la confidencialidad de la información hecha por la sociedad demandada en el mismo reglamento, toda vez que como ha quedado de manifiesto, es cuestionable que se pueda hablar de traspaso de información cuando ya estaba entregada y que se pueda hablar de confidencial, cuando por el desarrollo temporal de los hechos ya no lo era, pero por sobre todo, por que la importancia invocada no era tal que justificase desconocer la protección de un derecho fundamental como lo es el de la inviolabilidad de las comunicaciones privadas y luego de ella el derecho a la intimidad.

Con lo razonado, este juez, como lo expresará en lo resolutivo, estima que el demandado no ha dado suficientes fundamentos de las medidas adoptadas y su proporcionalidad, por lo que necesariamente deberá instarse por la protección del derecho fundamental del trabajador, materializando con ello lo tutela judicial efectiva del mandato contenido en el inciso primero del artículo quinto del Código del Trabajo, que ha dispuesto que el ejercicio de las facultades que la ley le reconoce al empleador, tienen como límite el respeto a las garantías constitucionales de los trabajadores, en especial cuando pudieran afectar la intimidad, la vida privada o la honra de estos. La norma citada viene a ser sin 
duda, el correlato laboral, del principio de vinculación directa, contenido en el inciso segundo del artículo sexto de nuestra Constitución Política de la República, el cual dispone que sus preceptos -entre ellos los derechos y garantías reconocidos- obligan tanto a titulares como integrantes de los órganos del Estado, como a toda persona, institución o grupo.

NOVENO. Determinación del monto de la indemnización sancionatoria. Nuestro nuevo procedimiento de tutela ha venido a crear un cauce procesal para la protección de derechos no patrimoniales, vinculados, más que al intercambio de servicios por dinero, a la dimensión moral del sujeto entendido como ciudadano. Con todo, frente al reconocimiento de lo complejo y agotadoras que pueden ser las relaciones entre particulares en el ámbito de la empresa, luego de destruida la comunidad de intereses, es que se ha privilegiado por sobre el reintegro laboral, lo cual sería lo único que dejaría verdaderamente indemne un despido vulneratorio, el establecimiento de una indemnización sancionatoria, que va de seis a once meses de la última remuneración mensual. Establecida la extensión del tramo por el legislador, corresponde al juez fijar en concreto el cuantum de la sanción, donde éste en particular tendrá en consideración que la trabajadora perdió su empleo a raíz de esta vulneración, a días de cumplir un año de servicio, lo que le habría significado una indemnización por tal concepto correspondiente a una remuneración; luego lo determinante debe ser la gravedad de la vulneración efectuada por el empleador, la que se determina a partir del derecho fundamental afectado, de la intensidad de afectación del mismo y de la conducta que haya tenido la sancionada en relación al debido respeto que se debe tener de este tipo de derechos; todo ello lleva a estimar que la sanción debe ser moderada, pero no el mínimo legal, como se expresará en lo resolutivo.

Por estas consideraciones y lo dispuesto en los artículos 1,6 inciso $2^{\circ}$ y $3^{\circ}$ y $19 \mathrm{~N}^{\circ} 4$ y $5^{\circ}$ de la Constitución Política de la República; artículo 17 del Pacto Internacional de Derechos Civiles y Políticos, y 11 de la Convención Americana sobre Derechos Humanos; y artículos 1, 2, 3, 4, 5 a 11, 21, 22, 34, 35, 41, 42, 44, 54 a 58, 153, 154, 156, 160 $\mathrm{N}^{\circ} 7,161,162,163,168,172,173,176,178,184,415,420,423,425$ a 432,434 a 438, 440 a 462 y 485 a 495 del Código del Trabajo; se resuelve:

-Que se acoge la demanda interpuesta por doña María Natalia Madrid Obregón en contra de su ex empleadora Sociedad de Profesionales Kronos Ltda., representada legalmente por don Jorge Godoy Frías y en consecuencia se declara:

I. Que el despido efectuado por Sociedad de Profesionales Kronos Ltda., ha sido consecuencia directa de la vulneración de la garantía de inviolabilidad de toda forma de comunicación privada que asistía a doña María Natalia Madrid Obregón.

II. Dicho despido, en consecuencia, es vulneratorio de derechos fundamentales, por lo que la sociedad demandada deberá pagar a doña María Natalia Madrid Obregón las siguientes indemnizaciones:

a) $\$ 864.100$ por concepto de indemnización por omisión de aviso previo;

b) $\$ 6.048 .700$ por concepto de indemnización sancionatoria, correspondiente a siete meses de la última remuneración mensual; 
c) No se da lugar a las indemnizaciones del artículo 163 del Código del Trabajo y su respectiva recarga contemplada en el artículo 168 del mismo cuerpo legal, por no haber enterado la trabajadora un año de servicio.

III. Las sumas antes señaladas deberán ser pagadas debidamente reajustadas y con intereses.

IV. La sociedad vencida deberá, en un plazo prudencial que no exceda los próximos dos meses, incluir en su reglamento interno una regulación expresa relativa a las condiciones, frecuencia y oportunidad del uso de los medios de comunicación electrónicos que proporciona la empresa; definiendo, en específico, un procedimiento para la revisión de los equipos y de la información que quede almacenada en carpetas y sitios no privados.

V. En razón de haber tenido motivos plausibles para litigar no se condena en costas a la demandada.

Devuélvase a los intervinientes, las pruebas aportadas.

Ejecutoriada que sea la presente sentencia, remítase copia de ella a la Dirección del Trabajo, a través de la Inspección Regional de Copiapó respectiva. Además, cúmplase lo resuelto en ella dentro de quinto día, en caso contrario pasen los antecedentes a la unidad de cumplimiento ejecutivo del Tribunal.

Regístrese y comuníquese.

R.U.C. 08-4-0001305-6

R.I.T. T-1-2008

Dictada por don César Alexanders Torres Mesías, Juez Titular del Juzgado de Letras del Trabajo de Copiapó.

\section{COMENTARio}

Esta sentencia constituye una completa novedad en nuestro ordenamiento jurídico, ya que es una de las primeras que dicta la nueva judicatura laboral en el procedimiento especial de tutela previsto en los Arts. 485 y ss. del Código del Trabajo. De ahí la exigencia impuesta a la academia de estudiar esta importante resolución, que, aunque de primera instancia, marca un hito relevante para la aplicación que hagan de estas nuevas categorías los jueces laborales.

Es de sobra conocido que este nuevo procedimiento de tutela de derechos fundamentales, previsto en el Código de Trabajo, a partir de la Ley No 20.087 de 2006, fue incorporado a nuestro ordenamiento como un mecanismo reforzado de protección de los derechos fundamentales de los trabajadores. Se trataba de dar plena vigencia a algunos de los derechos ya contenidos en la Constitución Política de la República, pero cuya eficacia vía el Recurso de Protección se estimaba débil, a partir de una interpretación restrictiva de éstos por los tribunales ordinarios. En el fondo se pretendía proteger de forma más 
eficaz los derechos fundamentales de los trabajadores en la empresa, reconociendo a éstos el carácter de "ciudadanos", del que ya gozaban fuera del ámbito laboral. ${ }^{1}$

Lo anterior permite explicar, sin duda, el entusiasmo con que la doctrina laboral más progresista ha recibido esta reforma, declarándose abiertamente partidaria de esta nueva manifestación de eficacia directa e inmediata de las normas constitucionales y, derivando de lo mismo, la eficacia horizontal de los derechos fundamentales. ${ }^{2}$ Ello ha impedido una reflexión más serena por esta misma doctrina, confundiendo conceptos básicos de la teoría constitucional, desnaturalizando algunos conceptos elementales de derecho constitucional y otorgando una aplicación desmesurada y peligrosa a la doctrina germana de la drittwirkung. ${ }^{3}$

Probablemente este mismo entusiasmo explica la sentencia transcrita más arriba, ya que con una energía e ímpetu poco habitual en nuestros tribunales, el juez laboral utiliza una amplia variedad de categorías doctrinales de la teoría de los derechos fundamentales, las que siendo correctas, son completamente ajenas a la cuestión debatida en estos autos. En efecto, como se verá a continuación, el juez laboral en este caso hace referencias extensas a la aplicación de los derechos fundamentales en el ordenamiento jurídico, explicando latamente el método de ponderación, guiado por el principio de proporcionalidad según él mismo declara, lo que constituye una manifestación elocuente de su erudición, pero que es innecesaria y ajena al conflicto planteado.

En concreto, la sentencia en comento plantea la cuestión de la intervención y utilización de comunicaciones electrónicas en el marco de la proporcionalidad de la medida adoptada por el empleador y en su uso legítimo o no para justificar el despido por parte del empleador. Aún más, la discusión inicial la plantea a partir de la ausencia de norma legal o reglamentaria interna de la empresa que resuelva el conflicto, y como el empleador, a partir de dicha omisión, interviene la comunicación electrónica y despide a la trabajadora por el contenido mismo del mensaje.

En mi opinión, todo este razonamiento es completamente erróneo y revela un problema en el conocimiento de las categorías fundamentales del Derecho Constitucional. En efecto, el punto de partida de este conflicto -que, recuérdese, es de tutela de derechos fundamentales- debe hacerse a partir del derecho fundamental mismo invocado, esto es, el derecho a la "inviolabilidad de toda forma de comunicación privada", la que sólo puede "interceptarse, abrirse o registrarse en los casos y formas determinados por la ley" (Art. $19 \mathrm{~N}^{\circ} 5$ de la Constitución Política de la República).

1 Ver, Gamonal, S., El procedimiento de tutela de derechos laborales, LexisNexis, Santiago, 2007, pp. 7-10.

${ }^{2}$ Ver, entre otros, Gamonal, S., El procedimiento de tutela de derechos laborales, ob. cit., y Ugarte, J.L., "La tutela de derechos fundamentales y el derecho del trabajo: de erizo a zorro", en Revista de Derecho, Universidad Austral de Chile, Vol. XX, No 2, diciembre 2007, pp. 49-67.

${ }^{3}$ Sobre el contenido de esta doctrina germana y su interpretación y aplicación en el derecho chileno, ver Aldunate, E. "El efecto de irradiación de los derechos fundamentales", en La constitucionalización del derecho chileno, Ferrada, J.C. (coor.), Editorial Jurídica de Chile/Universidad Austral de Chile, Santiago, 2003 , pp. 13 y ss. 
En primer lugar, este derecho tiene sus antecedentes en la declaración de la Asamblea Nacional revolucionaria de 1790, que consagró el principio del "secreto de las cartas" como "inviolable". 4 Su fundamento radica en el resguardo y protección de la libertad personal, ${ }^{5}$ pero se enlaza muy fuertemente con la libertad de pensamiento, la libertad política y la libertad de empresa. ${ }^{6}$ En este contexto, la inviolabilidad de la correspondencia se transforma en una garantía objetiva de los ciudadanos contra una posible intervención del poder estatal o privado en la vida privada, intimidad o libertad de las personas, impidiendo el resurgimiento de un estado policial en nuestro medio.

Ahora bien, esta protección constitucional de las comunicaciones privadas debe extenderse no sólo a los mensajes contenidos en cartas o notas escritas, sino a toda forma de transmisión de mensajes entre personas. Así, la jurisprudencia y la doctrina entienden que gozan de esta protección a las comunicaciones privadas los mensajes trasmitidos por radiofonía, telégrafos, teléfonos, Internet o cualquier otra forma idónea, ya que en todos estos casos el propósito del emisor es establecer una relación privada con el otro comunicante, la que está amparada por el secreto. ${ }^{7}$

No obstante lo anterior, esta protección de las comunicaciones privadas no es absoluta, en la medida que existen ciertos valores o bienes jurídicos de mayor entidad para la sociedad política que habilitarían, restrictivamente, una modulación de este derecho, mediante una intervención o registro, pero bajo una estricta reserva legal. Así, por ejemplo, la salvaguardia de las instituciones democráticas en términos generales en el derecho comparado se ha aceptado como una causal habilitante para la interceptación de las comunicaciones privadas. ${ }^{8}$ En nuestro medio, la persecución criminal ha sido aceptada como una cláusula de excepción a la afectación de este derecho, pero siempre que una ley lo autorice y previa orden judicial previa. ${ }^{9}$

En este contexto, y para el caso concreto que plantea esta sentencia -y más allá de la discusión acerca de la aplicación directa o indirecta del derecho fundamental-, la interrogante fundamental debe estar dada entonces por la determinación, por un lado, del carácter de comunicación privada que tiene la comunicación privada intervenida por la empresa a la actora; y, por otro, por la existencia de una ley que permita la intercepción, apertura o registro de esta comunicación. Respecto de lo primero, parece no haber dudas, ya que el propio empleador reconoce en su contestación, y así lo da por establecido la sentencia, que el sistema de comunicación de la actora era claramente personal, utilizándolo con una finalidad estrictamente privada, al grado que le señala

${ }^{4}$ Fernández Segado, F., El sistema constitucional español, Dykinson, Madrid, 1992, p. 228.

${ }^{5}$ Gimeno Sendra, V. et alli., Los derechos fundamentales y su protección jurisdiccional, Editorial Colex, Madrid, 2007, p. 157.

${ }^{6}$ Vivanco, A., Curso de Derecho Constitucional, tomo II, Ediciones Universidad Católica de Chile, Santiago, 2006, p.365.

${ }^{7}$ Idem, p.365. En el ámbito europeo, ver Arzoz, X, “Artículo 8. Derecho al respeto a la vida privada y familiar", en Convenio Europeo de Derechos Humanos, Thomson/Civitas, Madrid, 2004, pp. 316-317.

${ }^{8}$ Arzoz, X, "Artículo 8. Derecho al respeto a la vida privada y familiar", p. 319.

${ }^{9}$ Vivanco, A., Curso de Derecho Constitucional, tomo II, p. 365. 
a su comunicante su intención de mantener en reserva lo expuesto por esta vía. En relación a lo segundo, tampoco parece haber dudas de la inexistencia de una norma legal que autorice al empleador la intercepción, apertura o registro de esta comunicación, cuestión que también deja establecida la sentencia, ampliando la constatación -errónea y peligrosamente- a la ausencia de disposición en tal sentido en el reglamento interno de la empresa.

Así, en este caso concreto, el empleador no tenía fundamento constitucional o legal alguno para interceptar, abrir o registrar la comunicación privada, lo que llevaría necesariamente a sostener la inconstitucionalidad de la medida por vulneración del Art. 19 $\mathrm{N}^{\circ} 5$ de la Constitución Política de la República, ya sea por aplicación directa de este precepto o, por vía indirecta, constatando la inconstitucionalidad de la aplicación de la causal de despido, fundada en una conducta irregular como base para aplicar éste.

En suma, parece evidente que los intrincados razonamientos del juez acerca de la proporcionalidad de la medida, el derecho a la tutela judicial efectiva y la confidencialidad de la información transmitida por la actora en su comunicación electrónica carecen de absoluta relevancia en este caso, bastando para resolver la cuestión debatida la aplicación simple y sencilla del precepto constitucional. Por supuesto esto es menos lucido que lo razonado por el juez, pero más correcto y ajustado a nuestro sistema constitucional, lo que parece debiera ser la tarea de un juez en un Estado de Derecho. Sin duda, es mejor la vida sencilla. 